\title{
PENGARUH SIKAP MENABUNG DAN ORIENTASI MASA DEPAN TERHADAP PERENCANAAN DANA PENSIUN PADA PEKERJA SWASTA DI KOTA SURABAYA
}

\author{
Muhammad Arfan Hajam \\ Universitas Islam Negeri (UIN) Sunan Ampel, Surabaya, Indonesia \\ muhammadarfanhajam@gmail.com \\ https://doi.org/10.46367/iqtishaduna.v9i2.239
}

Received: Oct 8, 2020 Revised: Nov 8, 2020 Accepted: Nov 13, 2020 Published: Dec 17, 2020

\begin{abstract}
The purpose of this research was to determine the effect of saving attitudes and future orientation on retirement planning Population in this research are private workers in the city of Surabaya. The sample in this research used 200 samples. The data collection techniques used questionnaires. The data analysis technique used SEM-PLS. The result of this research is that saving attitude and future orientation influences retirement planning with a percentage of influence of $26 \%$, while the remaining $74 \%$ is influenced by other variables that are not included in this research model.
\end{abstract}

Keywords: Saving Attitude, Future Orientation, Retirements Planning.

\begin{abstract}
ABSTRAK
Tujuan penelitian ini adalah untuk mengetahui pengaruh sikap menabung dan orientasi masa depan terhadap perencanaan dana pensiun. Populasi dalam penelitian ini adalah pekerja swasta di Kota Surabaya. Sampel dalam penelitian ini menggunakan sebanyak 200 orang. Teknik pengumpulan data menggunakan kuesioner. Teknik analisis data menggunakan SEM-PLS. Hasil dari penelitian ini menunjukkan bahwa sikap menabung dan orientasi masa depan berpengaruh terhadap perencanaan dana pensiun dengan persentase pengaruh sebesar $26 \%$, sedangkan sisanya $74 \%$ dipengaruhi oleh variabel lain yang tidak dimasukan dalam model penelitian ini.
\end{abstract}

Kata Kunci: Sikap menabung, Orientasi Masa depan, Perencanaan Dana pensiun.

\section{PENDAHULUAN}

Setiap orang akan senantiasa berusaha untuk mencapai kehidupan yang sejahtera di masa pensiun. Kesejahteraan seseorang dapat tercapai apabila seseorang mampu meraih kemandirian secara finansial, dimana seseorang sudah mampu bebas dari masalah finansial. Keinginan seseorang untuk mencapai kemandirian finansial di masa pensiun merupakan suatu harapan yang dapat diperoleh melalui perencanaan dana pensiun yang matang. Perencanaan dana pensiun dimulai dari seseorang mencari informasi sebanyak mungkin mengenai perencanaan dana pensiun. Informasi keuangan tentang dana pensiun akan 
menjadikan seseorang memiliki kepercayaan diri untuk menyiapkan dana pensiun sedini mungkin.

Menurut Otoritas Jasa keuangan (OJK) dalam (Ardianto 2019) bahwa OJK mencatat jumlah peserta dana pensiun pada tahun 2018 mengalami peningkatan sebesar 179.362 orang atau 4,03\% secara year on year (yoy). Hanya kepesertaan dari Dana Pensiun Lembaga Keuangan (DPLK) yang mengalami peningkatan signifikan menjadi sebanyak 3,24 juta orang. Jumlah peserta naik sebesar 6,03\% (yoy) atau sebanyak 183,2 ribu orang. Sedangkan peserta untuk Dana Pensiun Pemberi Kerja (DPPK) mencapai sebanyak 801,2 ribu orang. Penurunan terjadi pada peserta aktif sebesar 2,77\% (yoy) atau berkurang sebanyak 22,8 peserta. Namun, peserta pasif meningkat $3,13 \%$ atau bertambah 18 ribu peserta. Penurunan DPPK juga dipengaruhi kondisi sebagian besar dana pensiun yang melakukan penutupan kepesertaan baru. Dalam lima tahun terakhir, kepesertaan pada DPLK juga menunjukan tren meningkat. Hal ini disebabkan oleh adanya perusahaan swasta baru yang mengikutsertakan pekerjanya ke DPLK ataupun perusahaan swasta yang melakukan pengalihan kepesertaan dana pensiunnya ke DPLK. Di sisi lain, membuat portofolio DPPK tercatat terus menurun. Pada 2014, jumlah peserta DPPK dan DPLK memiliki portofolio masing-masing sebesar $36,84 \%$ dan $63,16 \%$. Sampai pada tahun 2018, portofolio peserta DPPK menurun menjadi 30,1\%, sedangakan peserta DPLK meningkat menjadi sebesar 69,9\%. Hal ini mengindikasikan bahwa para pemilik perusahaan swasta di Indonesia sudah mulai memikirkan tentang kesejahteraan masa pensiun para pekerja yang bekerja di perusahaan swasta agar mendorong para pekerja lebih produktif dalam bekerja. Selain itu, adanya keinginan perusahaan untuk menyiapkan dana pensiun untuk para pekerja juga perlu dibarengi oleh motivasi para pekerja untuk turut melakukan perencanaan dana pensiun sedini mungkin agar tercapai kemandirian finansial di masa pensiun.

Para pekerja akan berusaha mempersiapkan masa pensiun yang sejahtera, yang dimulai dengan menyisihkan sebagian penghasilan yang dimiliki dengan cara menabung sedikit demi sedikit. Hal ini tentunya akan membentuk pola pikir yang baru mengenai pentingnya melakukan perencanaan dana pensiun demi mewujudkan kemandirian finansial di masa tua. Perilaku perencanaan dana pensiun adalah suatu perilaku ataupun tindakan yang dilakukan seseorang untuk menyisihkan sebagian dana yang dimiliki guna kesejahteraan hidup di masa depan (Moorthy et al. 2012). Perencanaan dana pensiun yang matang sejak dini setidaknya akan mampu memberikan solusi keuangan di masa depan. Ada berbagai cara yang dapat dilakukan seseorang untuk mengumpulkan dana pensiun, namun yang paling utama adalah harus memiliki perencanaan tentang bagaimana para pekerja akan pensiun nantinya. Cara menabung sedikit demi sedikit untuk memperoleh dana pensiun adalah cara yang paling mudah dibandingkan cara lainnya. Pensiun dari pekerjaan sebagai karyawan bukan berarti para pekerja berhenti bekerja secara produktif sebab tidak ada manusia di dunia ini yang ingin berdiam diri dan tidak melakukan sesuatu yang produktif dalam hidupnya.

Faktor sikap menabung seseorang akan mempengaruhi seseorang dalam melakukan perencanaan dana pensiun. Payne et al. (2014) mengemukakan bahwa sikap pada keuangan seperti menabung dapat mempengaruhi perilaku perencanaan dana pensiun seseorang. Hal senada juga dikemukakan oleh (Sabri 
and Juen 2014) bahwa faktor sikap menabung memiliki pengaruh yang positif terhadap perencanaan dana pensiun pekerja wanita di Malaysia. Kimiyaghalam et al. (2017) mengemukakan bahwa terdapat pengaruh positif sikap menabung seseorang terhadap perencanaan dana pensiun dan juga terdapat pengaruh secara positif sikap menabung dalam memediasi orientasi masa depan dan literasi keuangan terhadap perencanaan dana pensiun seseorang. Brandstätter (2005) mengemukakan bahwa kepribadian yang dimiliki seseorang mempengaruhi sikap menabung seseorang. Seseorang yang tidak memiliki perencanaan dana pensiun yang baik, cenderung membelanjakan atau menghabiskan uangnya untuk memenuhi keinginan yang bersifat konsumtif. Sering kali uang yang dibelanjakan bukan untuk keperluan penting, ketika mereka melihat sesuatu barang yang menarik maka tanpa perlu berpikir panjang, seseorang akan merasakan dorongan yang kuat untuk menghabiskan uang dan memakainya secara tidak terkontrol tanpa perlu meyisihkan sebagian uang tersebut untuk keperluan yang lebih penting. Seseorang memiliki kecenderungan dalam membelanjakan uang yang dimiliki untuk keinginan mereka pada saat melihat barang yang diinginkan.

Faktor lain yang mempengaruhi perencanaan dana pensiun adalah orientasi masa depan. Moorthy et al. (2012) mengemukakan bahwa orientasi masa depan yang berdasarkan pada tujuan hidup di masa pensiun akan mempengaruhi seseorang dalam melakukan perencanaan dana pensiun. Orientasi masa depan merupakan harapan dan perhatian individu yang terbentuk mengenai masa depan dan perencanaan dalam mewujudkannya. Kimiyaghalam et al. (2017) mengemukakan bahwa terdapat pengaruh positif orientasi masa depan seseorang terhadap perencanaan dana pensiun.

Penelitian yang dilakukan oleh Mahdzan and Tabiani (2013) memaparkan bahwa faktor demografi yang mempengaruhi perilaku seseorang yang meliputi faktor usia, jenis kelamin, tingkat pendidikan, jumlah anak (tanggungan), status pernikahan, dan pengalaman bekerja. Pendapat lain yang memperkuat adanya pengaruh faktor demografi terhadap perencanaan dana pensiun adalah penelitian yang dilakukan oleh Moorthy et al. (2012) yang memaparkan bahwa faktor demografi yang meliputi usia, tingkat pendidikan dan tingkat pendapatan berpengaruh positif terhadap perencanaan dana pensiun. Berdasarkan masalah dan beberapa penelitian tersebut, maka penulis bertujuan untuk mengkaji pola hubungan sikap menabung dan orientasi masa depan terhadap perencanaan dana pensiun dan faktor demografi memoderasi orientasi masa depan terhadap perencanaan dana pensiun pekerja swasta di Kota Surabaya.

\section{TELAAH LITERATUR}

\section{Perencanaan Dana Pensiun}

Perilaku perencanaan dana pensiun adalah suatu perilaku ataupun tindakan yang dilakukan seseorang untuk menyisihkan sebagian dana yang dimiliki guna kesejahteraan hidup di masa depan (Moorthy et al. 2012). Penelitian ini juga menunjukkan bahwa semakin muda usia seseorang dengan rentang usia antara 2635 tahun maka besar kemungkinan pekerja tersebut memiliki sudut pandang serta perilaku yang lebih baik dalam melakukan perencanaan dana pensiun sejak dini, karena pekerja memiliki banyak waktu luang untuk mempersiapkan masa pensiun (Moorthy et al. 2012). Perilaku perencanaan keuangan yang sudah dimiliki akan 
menjadikan suatu kebiasaan atau habit yang selalu dilakukan oleh masyarakat dalam melakukan kegiatan apapun. Pada saat masyarakat memiliki kebiasaan dalam melakukan perencanaan keuangan yang baik seperti menyisihkan sebagian uang untuk ditabung, maka besar kemungkinan masyarakat mampu membagi komposisi kebutuhan dan kewajiban untuk keberlangsungan hidupnya dimasa depan (masa pensiun). Hal tersebut dapat dikatakan juga bahwa masyarakat yang memiliki pola perilaku perencanaan keuangan yang baik akan lebih terencana dalam menghadapi masa pensiun dibandingkan dengan seseorang yang tidak menerapkan pola perilaku keuangan yang baik yang ditunjang dengan tingkat literasi keuangan yang memadai (Lusardi and Mitchell 2014). Nejati et al. (2015) mengemukakan bahwa perencanaan dana pensiun yang baik ditentukan oleh tingkat literasi keuangan yang dimiliki. Hal yang sama juga dikemukan Selvadurai et al. (2018) bahwa perencanaan dana pensiun yang baik ditunjang dengan pengelolaan keuangan dan literasi keuangan yang baik. Seseorang yang merencanakan dana pensiun yang baik harus memiliki literasi keuangan yang baik agar dalam menyisihkan sebagian uang yang dimiliki dapat memiliki keuntungan di masa depan (Rooij et al. 2011). Selain itu, merujuk pada penelitian Moorthy et al. (2012) dikemukakan bahwa terdapat tiga indikator yang digunakan untuk mengukur perilaku perencanaan dana pensiun yaitu kesiapan keuangan untuk dana pensiun, standar hidup untuk dana pensiun, dan pengeluaran saat pensiun. Indikator tersebut akan digunakan untuk mengukur variabel perencanaan dana pensiun dan akan diperoleh interpretasi hasil adalah seorang pekerja sangat tidak terencana, tidak terencana, kurang terencana, terencana atau sangat terencana dalam melakukan perencanaan dana pensiun.

\section{Sikap Menabung}

Brandstätter (2005) mengemukakan bahwa kepribadian yang dimiliki seseorang mempengaruhi sikap menabung seseorang. Seseorang yang tidak memiliki perencanaan dana pensiun yang baik, cenderung membelanjakan atau menghabiskan uangnya untuk memenuhi keinginan yang bersifat konsumtif. Sering kali uang yang dibelanjakan bukan untuk keperluan penting, ketika mereka melihat sesuatu barang yang menarik maka tanpa perlu berpikir panjang, seseorang akan merasakan dorongan yang kuat untuk menghabiskan uang dan memakainya secara tidak terkontrol tanpa perlu meyisihkan sebagian uang tersebut untuk keperluan yang lebih penting.

Seseorang lebih cenderung membelanjakan uang yang dimiliki untuk keinginan mereka pada saat melihat barang yang diinginkan. Lain halnya dengan seseorang yang memiliki perencanaan masa pensiun, menganggap uang sebagai sesuatu yang menjanjikan di masa depan, artinya uang yang dimiliki lebih memprioritaskan pada kebutuhan di masa pensiun. Seseorang cenderung berperilaku untuk menunda kesenangan dalam membelanjakan uang atau menyimpannya untuk tujuan kesejahteraan di masa pensiun dan hanya membelanjakan uang yang dimiliki sesuai dengan kebutuhan dan skala prioritas dalam hidupnya. Seseorang yang memiliki perencanaan dana pensiun akan selalu menyisihkan uang yang dimiliki dengan berbagai cara antara lain menabung, berinvestasi atau cara lainnya. Berdasarkan penelitian yang dilakukan Brandstätter (2005), ada tiga indikator penilaian tentang sikap menabung antara lain kepemilikan rekening tabungan, kepribadian atau karakter untuk menabung, dan 
psikologis ekonomis. Indikator tersebut akan digunakan untuk mengukur variabel sikap menabung dan interprestasi yang diperoleh adalah seorang pekerja memiliki sikap menabung yang sangat buruk, buruk, kurang baik, baik, atau sangat baik.

\section{Orientasi Masa Depan}

Moorthy et al. (2012) mengemukakan bahwa orientasi masa depan yang berdasarkan pada tujuan hidup di masa pensiun akan mempengaruhi seseorang dalam melakukan perencanaan dana pensiun. Orientasi masa depan merupakan harapan dan perhatian individu yang terbentuk mengenai masa depan dan perencanaan dalam mewujudkannya. Orientasi masa depan telah digambarkan sejauh mana konsekuensi masa depan dapat berpengaruh pada suatu tindakan saat seseorang mengambil keputusan untuk merencanakan dana pensiun. Orientasi masa depan merupakan suatu fenomena kognitif motivasional kompleks yang terdiri dari antisipasi dan evaluasi tentang seseorang di masa depan dalam interaksinya dengan lingkungan sekitarnya. Selain itu,orientasi masa depan sangat berkaitan pada harapan, tujuan, standar, rencana, dan strategi pencapaian tujuan di waktu yang akan datang.

Seseorang yang mempunyai literasi keuangan yang baik dan memiliki orientasi masa depan akan memiliki kemungkinan lebih besar untuk berpartisipasi dalam program dana pensiun, olehnya itu penting seseorang memiliki pengetahuan keuangan dan orientasi masa depan agar dapar merencanakan dana pensiun demi kesejahteraan di masa pensiun. Hal ini dikemukakan oleh Kimiyaghalam et al. (2017) yang menjelaskan bahwa orientasi masa depan dan literasi keuangan berpengaruh signifkan terhadap perencanaan dana pensiun. Berdasarkan penelitian yang dilakukan Moorthy et al. (2012), terdapat empat indikator penilaian yang digunakan dalam mengukur orientasi masa depan adalah Keinginan untuk tetap bekerja, cara pandang tentang masa depan, keinginan pensiun sejahtera dan keinginan untuk memiliki informasi tentang pensiun. Indikator tersebut akan digunakan untuk mengukur variabel orientasi masa depan dan interprestasi hasil adalah seorang pekerja yang memiliki orientasi masa depan sangat rendah, rendah, sedang, tinggi, atau sangat tinggi.

\section{Faktor Demografi}

Menurut Adiotomo and Samosir (2011) bahwa demografi merupakan ilmu yang mempelajari perubahan kependudukan mengenai perubahan jumlah, persebaran, dan komposisi atau struktur penduduk. Faktor demografi (demography factor) setiap individu turut menentukan bagaimana seseorang berperilaku terhadap keuangannya. Penelitian yang dilakukan oleh (Mahdzan and Tabiani 2013) memaparkan bahwa faktor demografi yang mempengaruhi perilaku seseorang yang meliputi faktor usia, jenis kelamin, tingkat pendidikan, jumlah anak (tanggungan), status pernikahan, dan pengalaman bekerja. Pendapat lain yang memperkuat adanya pengaruh faktor demografi terhadap perencanaan dana pensiun adalah penelitian yang dilakukan oleh Moorthy et al. (2012) yang memaparkan bahwa faktor demografi yang meliputi usia, tingkat pendidikan, dan tingkat pendapatan berpengaruh positif terhadap perencanaan dana pensiun. Dimensi yang digunakan pada penelitian ini, berkaitan faktor demografi memoderasi orientasi masa depan terhadap perencanaan dana pensiun adalah jumlah pendapatan dan jumlah tanggungan. Pemilihan dimensi jumlah pendapatan 
pada penelitian ini disebabkan karena pada umumnya sesmakin tinggi penghasilan seseorang maka akan lebih besar kemungkinan menyisihkan sebagaian uang yang dimiliki untuk keperluan masa depan jika dibandingkan seseorang dengan penghasilan yang rendah. Selain itu, pemilihan dimensi jumlah tanggungan pada penelitian ini disebabkan karena pada umumnya seseorang yang memiliki jumlah tanggungan yang banyak akan semakin berhati-hati dalam menggunakan uang yang dimiliki yang akan berpengaruh pada besarnya jumlah pengeluaran sehingga perlu kecermatan dalam menyisihkan sebagaian uang yang dimiliki agar dapat menyisihkan uang tersebut untuk keperluan masa depan termasuk melakukan perencanaan dana pensiun.

Berdasarkan penjelasan variabel penelitian tersebut maka dapat diperoleh sebuah kerangka penelitian untuk meneliti ada tidaknya pengaruh sikap menabung yang dimiliki pekerja di Kota surabaya terhadap perencanaan dana pensiun dan juga pengaruh orientasi masa depan pekerja di Kota Surabaya terhadap perencanaan dana pensiun yang dimoderasi secara positif atau tidak oleh faktor demografi dengan dimensi yang digunakan pada penelitian ini adalah jumlah pendapatan dan jumlah tanggungan. Adapun kerangka penelitian disajikan pada Gambar 1.

\section{Gambar 1 Kerangka Penelitian}

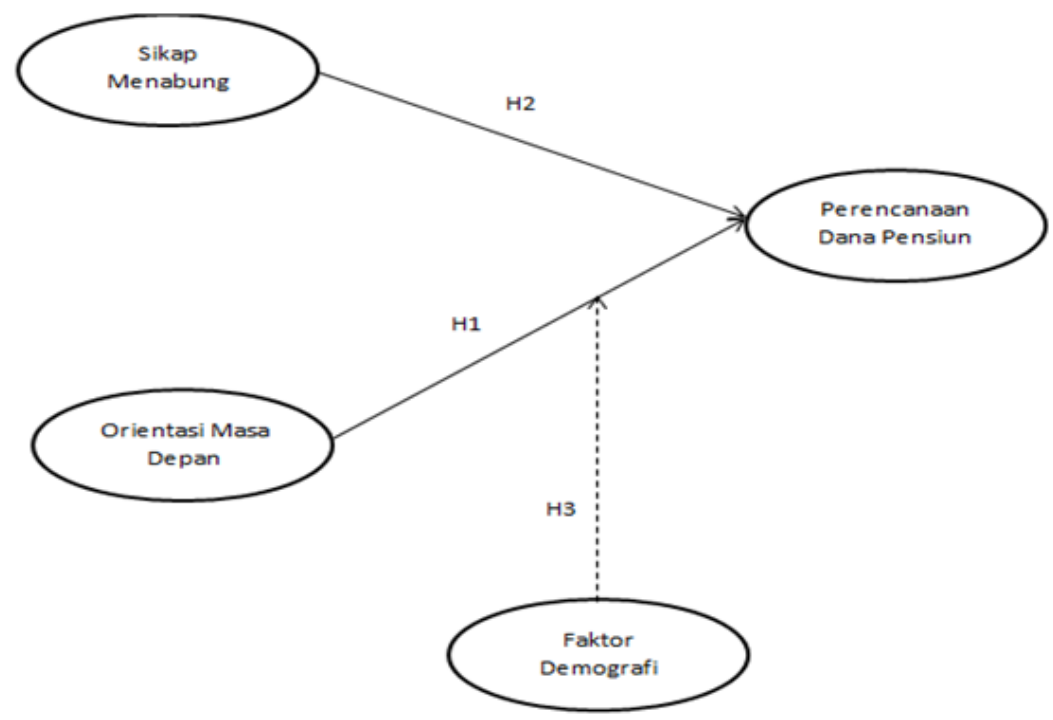

Gambar 1 dapat dijelaskan bahwa terdapat tiga hipotesis yang akan diteliti pada penelitian ini yaitu: $\mathrm{H} 1$ : Orientasi masa depan berpengaruh positif signifikan terhadap perencanaan dana pensiun. H2: Sikap menabung berpengaruh positif signifikan terhadap perencanaan dana pensiun. H3: Faktor demografi memoderasi orientasi masa depan terhadap perencanaan dana pensiun.

\section{METODE PENELITIAN}

Penelitian ini adalah penelitian kuantitatif yang menggunakan responden pekerja swasta di Kota Surabaya dengan teknik pengambilan sampling 
menggunakan purposive sampling yang dilakukan pada tahun 2020. Pada penelitian ini menggunakan jumlah sampel sebanyak 200 orang dengan metode pengumpulan data yang digunakan dalam penelitian ini adalah kuesioner. Teknik analisis data yang digunakan adalah menggunakan analisis SEM-PLS dengan alat uji statistik warpPLS 6.0 untuk uji menguji variabel dalam penelitian ini.

\section{HASIL DAN PEMBAHASAN PENELITIAN}

\section{Uji Validitas Data}

Kriteria pengujian validitas dilakukan dengan menggunakan nilai loading factors sebagai evaluasi outer model pada penelitian ini. Uji validitas dapat diukur berdasarkan tingkat dari nilai signifikansi yang diperoleh dari tiap pernyataan variabel sebesar $<0,05$. Data variabel dengan nilai signifikansi $<0,05$ dikatakan valid dan siap untuk digunakan pada penelitian ini. Adapun data uji valliditas disajikan pada Tabel 1, SM adalah Sikap Menabung, OMD adalah Orientasi Masa Depan, DPD adalah Perencanaan Dana Pensiun.

\section{Tabel 1 Uji Validitas}

\begin{tabular}{cccc}
\hline Variable & Item & Hasil Uji & Keterangan \\
\hline X1 & SM 1 & $<0,001$ & Valid \\
& SM 2 & $<0,001$ & Valid \\
& SM 3 & $<0,001$ & Valid \\
& SM 4 & $<0,001$ & Valid \\
& SM 5 & 0,004 & Valid \\
& SM 6 & $<0,001$ & Valid \\
\hline X2 & OMD 1 & $<0,001$ & Valid \\
& OMD 2 & $<0,001$ & Valid \\
& OMD 3 & 0,032 & Valid \\
& OMD 4 & $<0,001$ & Valid \\
& OMD 5 & $<0,001$ & Valid \\
& OMD 6 & $<0,001$ & Valid \\
& OMD 7 & $<0,001$ & Valid \\
& OMD 8 & $<0,001$ & Valid \\
\hline Y & PDP 1 & $<0,001$ & Valid \\
& PDP 2 & $<0,001$ & Valid \\
& PDP 3 & $<0,001$ & Valid \\
& PDP 4 & $<0,001$ & Valid \\
& PDP 5 & $<0,001$ & Valid \\
PDP 6 & $<0,001$ & Valid \\
& PDP 7 & $<0,001$ & Valid \\
PDP 8 & 0,018 & Valid \\
PDP 9 & $<0,001$ & Valid \\
\hline
\end{tabular}

Sumber: Data Olahan

\section{Uji Reliabilitas Data}

Suatu instrumen penelitian dapat dikatakan reliabel apabila nilai instrumen reliabilitas memenuhi. Uji reliabilitas pada penelitian ini dengan menggunakan 
nilai cronbach's dan nilai composite reliability sebagai evaluasi outer model pada penelitian ini. Reliabilitas data suatu variabel dapat dikatakan reliabel apabila nilai cronbach's alpha yang diperoleh $>0.6$ dan nilai composite reliability $>0.7$. Berikut data hasil uji nilai cronbach's dan nilai composite reliability yang disajikan pada Tabel 2.

\section{Tabel 2 Uji Reliabilitas}

\begin{tabular}{cccc}
\hline Variabel & $\begin{array}{c}\text { Cronbach's } \\
\text { Alpha }\end{array}$ & $\begin{array}{c}\text { Composite } \\
\text { Reliability }\end{array}$ & Keterangan \\
\hline SM & 0,613 & 0,734 & Reliabel \\
OMD & 0,814 & 0,893 & Reliabel \\
PDP & 0,604 & 0.729 & Reliabel \\
\hline \multicolumn{2}{l}{ Sumber: Data Olahan }
\end{tabular}

Dari Tabel 2 bahwa hasil uji reabilitas yang dilihat dari Cronbach's Alpa untuk masing masing varibel $>0.6$ dan Composite Reliability untuk masingmasing variabel $>0.7$, artinya data tersebut sudah reliabel dan layak untuk digunakan untuk penelitian.

\section{Uji Hipotesis}

Pengujian hipotesis adalah bentuk evaluasi inner model pada uji statistik pada penelitian ini. Pengujian hipotesis dengan menggunakan metode SEMPartial Least Square (PLS) dengan menggunakan alat uji WarpPLS 6.0 yang diketahui nilai dari masing-masing variabel dalam penelitian ini. Variabel yang diuji meliputi variabel orientasi masa depan, sikap menabung, faktor demografi, dan perencanaan dana pensiun. Hasil uji statistik disajikan pada Gambar 2.

\section{Gambar 2 Hasil Estimasi Model}

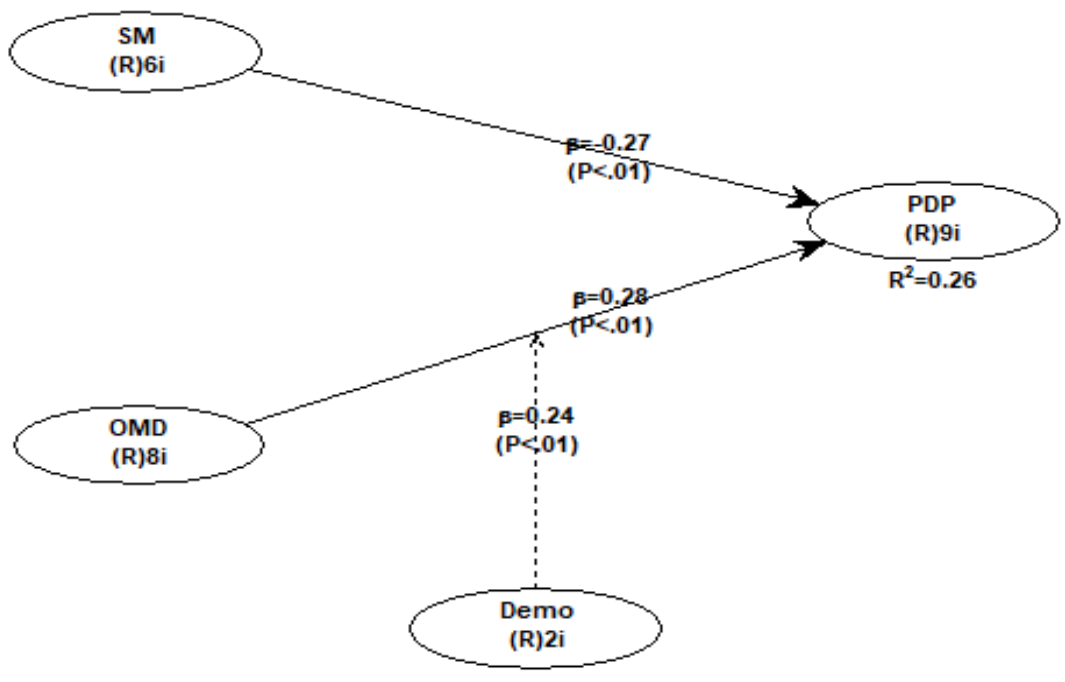

Sumber: Output warpPLS 6.0

Gambar 2 merupakan hasil ringkasan dari estimasi model sehingga dapat diperoleh hasil bahwa sikap menabung (SM) berpengaruh positif signifikan 
terhadap perencanaan dana pensiun (PDP) yang ditunjukkan nilai signifikansi < 0,01 atau nilai signifikansi $<0,05$ dan juga nilai koefisien $\beta 0,27$ yang diartikan bahwa besar pengaruh sikap menabung terhadap perencanaan dana pensiun sebesar 27\%. Hasil lainnya diperoleh bahwa orientasi masa depan (OMD) berpengaruh positif signifikan terhadap perencanaan dana pensiun (PDP) yang ditunjukkan nilai signifikansi $<0,01$ atau nilai signifikansi $<0,05$ dan juga nilai koefisien $\beta$ 0,28 yang diartikan bahwa besar pengaruh orientasi masa depan terhadap perencanaan dana pensiun sebesar $28 \%$, sedangkan faktor demografi memoderasi orientasi masa depan terhadap perencanaan dana pensiun yang ditunjukkan nilai signifikansi $<0,01$ atau nilai signifikansi $<0,05$. Nilai $R$-Square Coefficients diperoleh pada Gambar 2 dan disajikan pada Tabel 3.

\section{Tabel 3 R- Square Coefficients}

\begin{tabular}{ccl}
\hline Variabel & R-square & Keterangan \\
\hline PDP & 0.26 & $\begin{array}{l}\text { SM dan OMD memiliki pengaruh } \\
\text { terhadap PDP sebesar 26\% }\end{array}$ \\
\hline
\end{tabular}

Sumber: Data Olahan

$R$-Square (koefisien determinasi) digunakan untuk mengukur seberapa besar variabel endogen dipengaruhi oleh variabel lainnya. Berdasarkan tabel 3 diperoleh hasil $R$-Square (koefisien determinasi) untuk perencanaan dana pensiun sebesar 0,26 yang dapat diartikan bahwa $26 \%$ variabel perencanaan dan pensiun dapat dijelaskan oleh variabel sikap menabung dan orientasi masa depan sedangkan sisanya $74 \%$ dijelaskan oleh variabel lainnya.

Evaluasi path coefficients juga digunakan untuk menunjukkan seberapa besar pengaruh variabel eksogen (independent) kepada variabel endogen (dependent). Hasil ringkasan tabel estimasi model untuk path coefficients dan $p$ values pada Gambar 2 hasil estimasi model disajikan pada Tabel 4.

Tabel 4 Path Coefficients dan P-Values

\begin{tabular}{lcccc}
\hline \multicolumn{1}{c}{ Variabel } & $\begin{array}{c}\text { Nilai } \\
\text { Koefisien } \boldsymbol{\beta}\end{array}$ & $\begin{array}{c}\text { Arah yang } \\
\text { diharapkan }\end{array}$ & $\begin{array}{c}\boldsymbol{P} \text { - } \\
\text { values }\end{array}$ & $\begin{array}{c}\text { Hasil } \\
\text { Pengujian }\end{array}$ \\
\hline $\mathrm{OMD} \rightarrow \mathrm{PDP}$ & 0.27 & + & $<0.01$ & H1 Diterima \\
$\mathrm{SM} \rightarrow$ PDP & 0.28 & + & $<0.01$ & H2 Diterima \\
$\mathrm{DEMO*}$ OMD $\rightarrow$ PDP & 0.24 & + & $<0.01$ & H3 Diterima \\
\hline
\end{tabular}

Sumber: Data Olahan

\section{Orientasi Masa Depan Berpengaruh Positif Terhadap Perencanaan Dana Pensiun}

Berdasarkan hipotesis pertama dan Tabel 4, hasil estimasi model pada perangkat variabel orientasi masa depan menunjukkan bahwa $\mathrm{H} 1$ diterima. Orientasi masa depan berpengaruh positif signifikan terhadap perencanaan dana pensiun. Hal tersebut dibuktikan nilai koefisien $\beta$ sebesar 0.28 dan nilai signifikan p-value sebesar $<0.01$ atau kurang dari 0.05 . Hal ini dapat diartikan bahwa semakin tinggi orientasi masa depan seseorang maka perencanaan dana pensiun akan semakin terencana. 
Sikap Menabung Berpengaruh Positif Terhadap Perencanaan Dana Pensiun

Berdasarkan hipotesis kedua dan Tabel 4, hasil estimasi model pada perangkat variabel literasi keuangan menunjukkan bahwa $\mathrm{H} 2$ diterima. Sikap menabung berpengaruh positif signifikan terhadap perencanaan dana pensiun. Hal tersebut dibuktikan nilai koefisien $\beta$ sebesar 0.27 dan nilai signifikan $\mathrm{p}$-value sebesar $<0.01$. Hal ini dapat diartikan bahwa semakin tinggi sikap menabung yang dimiliki seseorang maka perencanaan dana pensiun akan semakin terencana.

\section{Faktor Demografi Memoderasi Orientasi Masa Depan Secara Positif Terhadap Perencanaan Dana Pensiun}

Berdasarkan hipotesis ketiga dan Tabel 4, hasil estimasi model pada perangkat variabel faktor demografi memoderasi literasi keuangan terhadap perencanaan dana pensiun menunjukkan bahwa H3 diterima. Hasil kriteria penerimaan variabel moderasi dapat dijelaskan bahwa faktor demografi berpengaruh secara parsial dari pengaruh orientasi masa depan terhadap perencanaan dana pensiun. Hal tersebut disebabkan oleh hubungan pengaruh dari ketiga variabel tersebut berpengaruh positif signifikan antara satu sama lainnya yang dibuktikan dengan nilai koefisien $\beta$ sebesar 0.24 dan nilai signifikan $\mathrm{p}$-value sebesar <0.01. Hal ini dapat diartikan bahwa semakin tinggi pendapatan dan jumlah tanggungan (faktor demografi) yang dimiliki seseorang dan memiliki orientasi masa depan yang tinggi akan menjadi pekerja swasta memiliki perencanaan dana pensiun yang semakin terencana.

\section{KESIMPULAN}

Hasil penelitian ini menunjukkan adanya pengaruh positif signifikan sikap menabung dan orientasi masa depan terhadap perencanaan dan pensiun serta faktor demografi dengan dimensi jumlah pendapatan dan jumlah tanggungan memoderasi sikap menabung terhadap terhadap perencanaan dana pensiun. Hal ini ditunjukkan dari hasil uji statistik yang menunjukkan nilai $p$-values untuk semua variabel uji bernilai < 0,05 yang dapat diartikan hipotesis dapat diterima.

Keterbatasan pada penelitian adalah penelitian ini masih terdapat variabel yang belum digunakan pada penelitian ini. Hal ini ditunjukkan dari hasil nilai $R$ Square (koefisien determinasi) untuk perencanaan dana pensiun sebesar 0,26 yang dapat diartikan bahwa sebesar $26 \%$ variabel perencanaan dana pensiun dapat dijelaskan oleh variabel sikap menabung dan orientasi masa depan sedangkan sisanya $74 \%$ dijelaskan oleh variabel lainnya. Selain itu, ruang lingkup penelitian masih mengkaji pada daerah perkotaan dan belum mengkaji daerah pedesaan ataupun lingkup propinsi dan nasional.

\section{DAFTAR PUSTAKA}

Adiotomo, Sri Moertiningsih dan Omas Bulan Samosir. 2011. Dasar-Dasar Demografi. Edisi Pertama. Jakarta: Salemba Empat.

Ardianto, Prisma. 2019. Penetrasi Dana Pensiun Masih Stagnan 60\%. diakses dari https://investor.id/finance/penetrasi-dana-pensiun-masih-stagnan-60, tanggal 29 Desember 2019. 
Brandstätter, Hermann. 2005. The Personality Roots of Saving - Uncovered from German and Dutch Surveys. In: Grunert K.G., Thфgersen J. (eds) Consumers, Policy and the Environment A Tribute to Folke Ölander. Springer: Boston, MA. https://doi.org/10.1007/0-387-25004-2_4.

Kimiyaghalam, Fatemeh, Meysam Safari, and Shaheen Mansori. 2017. "The Effects of Behavioral Factors on Retirement Planning in Malaysia". https://www.researchgate.net/publication/317719935_The_Effects_of_Beh avioral_Factors_on_Retirement_Planning_in_Malaysia.

Lusardi, Annamaria, and Olivia S. Mitchell. 2014. "The Economic Importance of Financial Literacy: Theory and Evidence”. Journal of Economic Literature 52 (1): 5-44. http://dx.doi.org/10.1257/jel.52.1.5.

Mahdzan, Nurul Shahnaz and Saleh Tabiani. 2013. "The Impact of Financial Literacy and Retirement Planning: New Evidence from the Rand American Life Panel". MMRC Working Paper. 157: 1-33.

Moorthy, Krishna, TD. Chelliah, and CS. Sien. 2012. "A Study on the Retirement Planning Behaviour of working Individuals in Malaysia”. International Journal of Academic Research in Economics and Management Sciences 1 (2): 54-72.

Nejati, Farzaneh, Mousa Ahmadi and Mona Lali. 2015. "The Impact of Financial Literacy on Retirement Planning and Household Wealth". Indian Journal of Fundamental and Applied Life Sciences 5 (1): 806-815.

Otoritas Jasa Keuangan Republik Indonesia. 2015. Peraturan Otoritas Jasa Keuangan Nomor 3/POJK.05/2015 tentang Investasi Dana Pensiun. Peraturan.

Payne, Scott H., Jeremy B. Yorgason and Jeffrey P. Dew. 2014. "Spending Today or saving for Tomorrow:The Influence of Family Financial Socialization on Financial Preparation for Retirement". Journal of Family and Economic 35: 106-118. https://doi.org/10.1007/s10834-013-9363-2.

Presiden Republik Indonesia. 1992. Peraturan Pemerintah Nomor 76 Tahun 1992 tentang Dana Pensiun Pemberi Kerja.

Presiden Republik Indonesia. 1992a. Peraturan Pemerintah Nomor 77 Tahun 1992 tentang Dana Pensiun Lembaga Keuangan.

Rooij, Maarten C.J. Van, Annamaria Lusardi and Rob J.M. Alessie. 2011. "Financial Literacy and Retirement Planning in Netherlands". Journal of $\begin{array}{lllll}\text { Economic } & \text { Psychology } & 32 & \text { (4): }\end{array}$ https://doi.org/10.1016/j.joep.2011.02.004.

Sabri, Mohamad Fazli, and Teo Tze Juen. 2014. "The Influence of Financial Literacy, Saving Behaviour, and Financial Management on Retirement Confidence among Women Working in the Malaysian Public Sector". Canadian Center of Science and Education 10 (14): 40-51. http://dx.doi.org/10.5539/ass.v10n14p40.

Selvadurai, Visyalini, Husaina Banu Kenayathulla and Saedah Siraj. 2018. "Financial Literacy Education and Retirement Planning in Malaysia". Malaysian Online Journal of Educational Management 6 (2): 41-66. https://doi.org/10.22452/mojem.vol6no2.3. 